\title{
The morphological stability and fuel production of commercial fibrous ceria particles for solar thermochemical redox cycling
}

\author{
Adam C. Gladen ${ }^{\mathrm{a}}$ and Jane H. Davidson ${ }^{\mathrm{a} 1}$
}

\begin{abstract}
Implementation of the solar thermochemical ceria redox cycle to split water and carbon dioxide depends in part on the morphological stability of a porous ceria substrate and the ability to acquire porous substrate in high volume. Here we evaluate the evolution of morphology and fuel production of ceria particles formed of fibers in a commercially relevant manufacturing process. The particles are evaluated over $1000 \mathrm{CO}_{2}$-splitting cycles $(56 \mathrm{hr})$ at $1773 \mathrm{~K}$ followed by sixteen temperature-swing cycles $(5.7 \mathrm{hr})$ with oxidation at $1073 \mathrm{~K}$. New particles are $78 \%$ porous with a specific surface area of $0.14 \mathrm{~m}^{2} \cdot \mathrm{g}^{-1}$ and a grain size of $3.7 \mu \mathrm{m}$. During isothermal cycling, the morphology stabilized after 500 cycles ( $28 \mathrm{hr}$ ) to $73 \%$ porosity, a surface face $0.08 \mathrm{~m}^{2} \cdot \mathrm{g}^{-1}$ and a grain size of $8 \mu \mathrm{m}$. The stabilized particles retained $89 \%$ of the peak cycle average rate of CO production. During temperature-swing cycling, the specific surface area decreased to $0.06 \mathrm{~m}^{2} \cdot \mathrm{g}^{-1}$. The mass-produced fibrous structures have adequately stable morphologies to produce fuel production performance similar to less scalable (lab-scale) ceria structures of similar pre-cycling surface area.
\end{abstract}

Keywords: cerium dioxide, solar thermochemical, morphology, redox 


\section{INTRODUCTION}

Spitting water and carbon dioxide via solar thermochemical, metal oxide redox cycles provides long-term storage of solar energy as hydrogen and synthesis gas, which can be used to produce electricity or converted to liquid hydrocarbon fuel. The non-stoichiometric cerium dioxide (ceria) cycle is an attractive approach because oxygen diffuses rapidly through the lattice (Chueh and Haile, 2010; Eyring, 1991), and there are no irreversible phase transitions between the fully oxidized and partially reduced states for non-stoichiometry less than 0.2 (Ackermann et al., 2014; Millot and Mierry, 1985). The cycle is represented by reactions (R1) and (R2a)/(R2b) for splitting $\mathrm{CO}_{2}$ and $\mathrm{H}_{2} \mathrm{O}$ respectively.

$$
\begin{aligned}
& \mathrm{CeO}_{2-\delta_{\text {ox }}} \rightarrow \mathrm{CeO}_{2-\delta_{\text {rd }}}+\frac{\Delta \delta}{2} \mathrm{O}_{2} \\
& \mathrm{CeO}_{2-\delta_{\text {rd }}}+\Delta \delta \mathrm{CO}_{2} \rightarrow \mathrm{CeO}_{2-\delta_{\text {ox }}}+\Delta \delta \mathrm{CO} \\
& \mathrm{CeO}_{2-\delta_{\text {rd }}}+\Delta \delta \mathrm{H}_{2} \mathrm{O} \rightarrow \mathrm{CeO}_{2-\delta_{\text {ox }}}+\Delta \delta \mathrm{H}_{2}
\end{aligned}
$$

Concentrated solar energy provides the process heat to drive the endothermic reduction step (R1). The change in nonstoichiometry between reduction and oxidation, $\Delta \delta=\delta_{\mathrm{rd}}-\delta_{\mathrm{ox}}$, represents the amount of fuel produced per mole of ceria.

The cycle can be operated isothermally or via a temperature-swing with oxidation hundreds of degrees cooler than reduction. The isothermal cycle has the same thermodynamic limitations as direct thermolysis of $\mathrm{CO}_{2}$ or $\mathrm{H}_{2} \mathrm{O}$, but with the benefit of separating the product gases into two streams. As demonstrated through implementation of a prototype reactor, isothermal cycling reduces thermal stresses on ceramic components, and facilitates continuous fuel production and effective heat recovery (Chandran and Davidson, 2016; Hathaway et al., 2016, 2015). On the other hand, solar-to-fuel efficiency is higher for a temperature-swing cycle (Brendelberger et al., 2015; Bulfin et al., 2015; Ermanoski et al., 2014; Jarrett et al., 2016; Krenzke and Davidson, 2015). Based on chemical thermodynamics 
(Panlener et al., 1975), reduction temperatures of $1673 \mathrm{~K}$ and preferably higher are required for meaningful fuel production per $\mathrm{kg}$ of ceria.

With such high reduction temperatures, a consideration for successful implementation of the cycle is the morphological stability of the ceria substrate. Porous structures featuring high surface area are desired to speed the rate of oxidation (Chueh and Haile, 2010; Venstrom et al., 2012), limit pressure drop (Bader et al., 2015; Venstrom et al., 2014), and enhance heat and mass transfer (Bader et al., 2015; Furler et al., 2014; Venstrom et al., 2014). However, the higher surface area ceria materials $\left(10\right.$ to $100 \mathrm{~m}^{2} \cdot \mathrm{g}^{-1}$ ) evaluated for this application (e.g., a three-dimensionally ordered macro-porous (3DOM) structure (Rudisill et al., 2013; Venstrom et al., 2012), a decomposition synthesized structure with a disordered, mesoporous morphology (Venstrom et al., 2012), and a wood-templated structure (Malonzo et al., 2014)) undergo densification and a corresponding significant loss of surface area below the target reduction temperature.

Morphologies with surface areas of the order $0.1 \mathrm{~m}^{2} \cdot \mathrm{g}^{-1}$, including pore formed monoliths (Chueh and Haile, 2010; Chueh et al., 2010; Hao et al., 2013; Rhodes et al., 2015; Venstrom et al., 2014), reticulated porous ceramic (RPC) (Furler et al., 2014, 2012a), and electrospun fibers (Gibbons et al., 2014), are more stable at or above $1673 \mathrm{~K}$ but still lose surface area over time. The impact of surface area on fuel production depends on the rate limiting mechanism and the thermodynamic driving force. For this reason, direct comparison of the rate of fuel production among the prior studies of different morphologies is generally not meaningful due to wide variation of test conditions, notably temperatures, gas flow rates, oxidizer, and cycle duration.

In early work to produce porous ceria substrates for this application, Cheuh et al. used a sacrificial pore former to fabricate pressed ceria monoliths with $65 \%-80 \%$ porosity and specific surface area of $0.1 \mathrm{~m}^{2} \cdot \mathrm{g}^{-1}$ (Chueh and Haile, 2010; Chueh et al., 2010). Over $416 \mathrm{hr}$ 
of redox cycling between $1773 \mathrm{~K}$ and $1073 \mathrm{~K}$ to split water, $\mathrm{H}_{2}$ production decreased $50 \%$ (Chueh and Haile, 2010). The decrease was attributed to an assumed loss of surface area based on a threefold increase in grain size. More recently, Rhodes et al. compared the CO production of a ceria monolith produced using a sacrificial graphite pore former to that of nano- and micron-diameter ceria powder (Rhodes et al., 2015). The results are consistent with the comparative studies of 3DOM (Rudisill et al., 2013; Venstrom et al., 2012) and woodtemplated structures (Malonzo et al., 2014) with commercial ceria powder; higher surface area yields faster fuel production.

RPC morphologies have been considered (Furler et al., 2014, 2012a) due to the relatively high effective thermal conductivity and low pressure drop possible for high porosity and large pore size foams (e.g. $90 \%$ porosity; 10 pores per inch). RPCs manufactured utilizing the replication method have specific surface areas on the order of $0.0001 \mathrm{~m}^{2} \cdot \mathrm{g}^{-1}$ (Furler et al., 2014). Furler et al. (Furler et al., 2014) used pore formers to increase the accessible surface area in the struts of ceria RPC. Over $50 \mathrm{hr}$ of cycling between $1773 \mathrm{~K}$ and $1273 \mathrm{~K}$, the surface area decreased from 0.095 to $0.089 \mathrm{~m}^{2} \cdot \mathrm{g}^{-1}$. After $120 \mathrm{hr}$ in air at $1773 \mathrm{~K}$, the surface area was $0.056 \mathrm{~m}^{2} \cdot \mathrm{g}^{-1}$.

Ceria structures formed from fibers are potentially a lower cost option than templated materials and RPC and are available commercially. However, not all fibrous materials are stable. Ceria "felt" which is available commercially for use in used in molten carbonate fuel cells was evaluated in a solar thermochemical reactor. The felt had an initial surface area of $\sim 6 \mathrm{~m}^{2} \cdot \mathrm{g}^{-1}$ (Furler et al., 2012a) but densified substantially after $\sim 8 \mathrm{hr}$ with a reduction temperature of approximately $1800 \mathrm{~K}$ (Furler et al., 2012b). On the other hand, electrospun $\mathrm{Ce}_{0.975} \mathrm{Zr}_{0.025} \mathrm{O}_{2}$ fibers retained an open porous structure over $29 \mathrm{hr}$ of cycling between $1673 \mathrm{~K}$ and $1073 \mathrm{~K}$ even as the specific surface area decreased from 0.6 to $0.34 \mathrm{~m}^{2} \cdot \mathrm{g}^{-1}$ 
(Gibbons et al., 2014). With reduction at $1773 \mathrm{~K}$, sintering was more extensive and fuel production decreased despite more favorable thermodynamics.

The encouraging behavior of the electrospun fibers at $1673 \mathrm{~K}$ motivated the development and evaluation of mm-sized fibrous ceria particles for use in a fixed bed isothermal solar thermochemical reactor (Bader et al., 2015; Bala Chandran et al., 2015; Chandran and Davidson, 2016; Hathaway et al., 2016, 2015; Venstrom et al., 2015, 2014). The selection of the size and morphology of the particles was driven by the desire to minimize pressure drop and temperature gradients in a packed bed, and to ensure gas phase diffusion was not rate limiting (Bader et al., 2015; Venstrom et al., 2014, 2012). The other motivation was the need to acquire kilograms of material coupled along with the desire to identify a commercially relevant synthesis approach. The fibers were developed in conjunction with an industrial partner and were formed in a proprietary process using a precursor method in which organic textiles are converted into ceramic oxide textiles. The textile is milled to obtain bulk fibers. The $5 \mathrm{~mm}$ diameter, $5 \mathrm{~mm}$ long cylindrical particles produced from the fibers were fired in air at $1873 \mathrm{~K}$ to stabilize the morphology prior to cycling at $1773 \mathrm{~K}$. The cost of the particles in kilogram quantities is high (on the order of 6000 US\$ per kg in 2016) because of the expense of development and the relatively high labor cost for a small production of $3 \mathrm{~kg}$. However, the manufacturing process for the base material is similar to the process used to produce high temperature refractory insulation. Thus, larger scale structures, similar to those produced for refractory insulation, could be made and will be less expensive than the smaller mm-sized particles. Based on discussion with the supplier, it is reasonable to expect an order of magnitude cost reduction for the particles and even greater cost reduction for larger structures if the market for ceria fiber structures expands. 
The durability of the fibrous particles was evaluated during isothermal $\mathrm{CO}_{2}$ splitting at

$1773 \mathrm{~K}$ for $56 \mathrm{hrs}$ followed by temperature-swing cycling at the same reduction temperature and oxidation at $1073 \mathrm{~K}$ for $6 \mathrm{hr}$. To help delineate the effects of thermochemical cycling and temperature on the morphological changes, evolution of particle morphology was also evaluated in a flow of air at $1773 \mathrm{~K}$.

\section{APPROACH}

\subsection{Isothermal Cycling}

The evolution of surface area, particle porosity, grain size and the rates of $\mathrm{O}_{2}$ and $\mathrm{CO}$ production was monitored in eight experiments of increasing duration from 0.056 to $55.56 \mathrm{hr}$, corresponding to 1 to 1000 redox cycles. The particles were in a packed bed held at $1773 \mathrm{~K}$ in a tube furnace. The cycling conditions are identical to those identified in prior work to provide the highest solar-to-fuel efficiency for swept gas reduction and isothermal $\mathrm{CO}_{2}$ splitting (Hathaway et al., 2015; Venstrom et al., 2015, 2014) and are listed in Table 1. For each isothermal experiment, four grams were loaded in a $75 \mathrm{~mm}$ long packed bed in a $9.5 \mathrm{~mm}$ diameter alumina tube. The tube was heated in a $300 \mathrm{~mm}$ long, single-zone electric tube furnace (Across TF1700) with a $135 \mathrm{~mm}$ long isothermal region. The furnace temperature was set to $1773 \mathrm{~K}$ using a shielded type-B thermocouple $( \pm 0.5 \%)$ located $1 \mathrm{~cm}$ from the outer surface of the alumina tube. Temperatures of the particles were measured with exposed type-B thermocouples placed at the upstream and downstream edges of the bed. The particles were heated at $5 \mathrm{~K} \cdot \mathrm{min}^{-1}$ and then held at $1773 \mathrm{~K}$ for ten minutes under an oxidizing flow of $\mathrm{CO}_{2}$ to establish an initial non-stoichiometry of 0.0214. Cycling was then initiated for 200 s cycles with a flow of $\mathrm{N}_{2}(99.998 \%$ pure with $<10$ ppm oxygen) for $100 \mathrm{~s}$ followed by reoxidation with $\mathrm{CO}_{2}\left(99.999 \%\right.$ pure) for $100 \mathrm{~s}$. The flow rates of $\mathrm{N}_{2}$ and $\mathrm{CO}_{2}$ were $1.67 \mathrm{~mL} \cdot \mathrm{s}^{-1} \cdot \mathrm{g}_{\text {ceria }}{ }^{-1}$, equal to the mass specific flow rates in the solar reactor (Hathaway et al., 
2015). After cycling, the ceria was cooled to room temperature in the oxidizing flow at a

cooling rate of $\leq 5 \mathrm{~K} \cdot \mathrm{min}^{-1}$. The gas flows were controlled automatically by mass flow controllers ( $\pm 0.3 \%$ ) and by electronic valves to ensure rapid switching between reduction and oxidation. The temperatures at the upstream and downstream edges of the bed are shown in Figure 1 for a representative cycle. The cycle-average temperature of the bed is $\sim 1774 \mathrm{~K}$. In agreement with prior work (Hathaway et al., 2015), the upstream temperature decreases slightly $(\sim 1 \mathrm{~K})$ during oxidation due to the higher heat capacity of $\mathrm{CO}_{2}$ relative to $\mathrm{N}_{2}$ at equivalent flows.

Table 1. Cycling Conditions.

\begin{tabular}{llll}
\hline Parameter & $\begin{array}{l}\text { Isothermal } \\
\text { Cycle }\end{array}$ & $\begin{array}{l}\text { Temperature- } \\
\text { swing Cycle }\end{array}$ & Unit \\
\hline $\mathrm{T}_{\mathrm{rd}}$ & 1773 & 1773 & $\mathrm{~K}$ \\
$\mathrm{~T}_{\mathrm{ox}}$ & 1773 & 1073 & $\mathrm{~K}$ \\
Reducing Gas & $\mathrm{N}_{2}$ & $\mathrm{~N}_{2}$ & - \\
$\dot{\mathrm{V}}_{\mathrm{rd}}^{\prime}$ & $1.67^{[\mathrm{a}]}$ & 16.67 & $\mathrm{~mL} \cdot \mathrm{s}^{-1} \cdot \mathrm{g}_{\text {ceria }}{ }^{-1}$ \\
$\tau_{\mathrm{rd}}$ & 100 & 300 & $\mathrm{~s}$ \\
Oxidizer & $\mathrm{CO}_{2}$ & $\mathrm{CO}_{2}(25 \% \mathrm{~mol})$, & - \\
$\dot{\mathrm{V}}_{\text {ox }}^{\prime}$ & $1.67^{[\mathrm{a}]}$ & 22.22 & $\mathrm{~mL} \cdot \mathrm{s}^{-1} \cdot \mathrm{g}_{\text {ceria }}{ }^{-1}$ \\
$\tau_{\text {ox }}$ & 100 & 240 & $\mathrm{~s}$ \\
$\tau_{\text {purge }}$ & $\mathrm{N} / \mathrm{A}$ & 120 & $\mathrm{~s}$ \\
Heating Rate & $\mathrm{N} / \mathrm{A}$ & 100 & $\mathrm{~K} \cdot \mathrm{min}^{-1}$ \\
Cooling Rate & $\mathrm{N} / \mathrm{A}$ & 200 & $\mathrm{~K} \cdot \mathrm{min}^{-1}$ \\
\hline
\end{tabular}

[a] Volumetric flow rates are reported at standard conditions of $298.15 \mathrm{~K}$ and $100 \mathrm{kPa}$ 


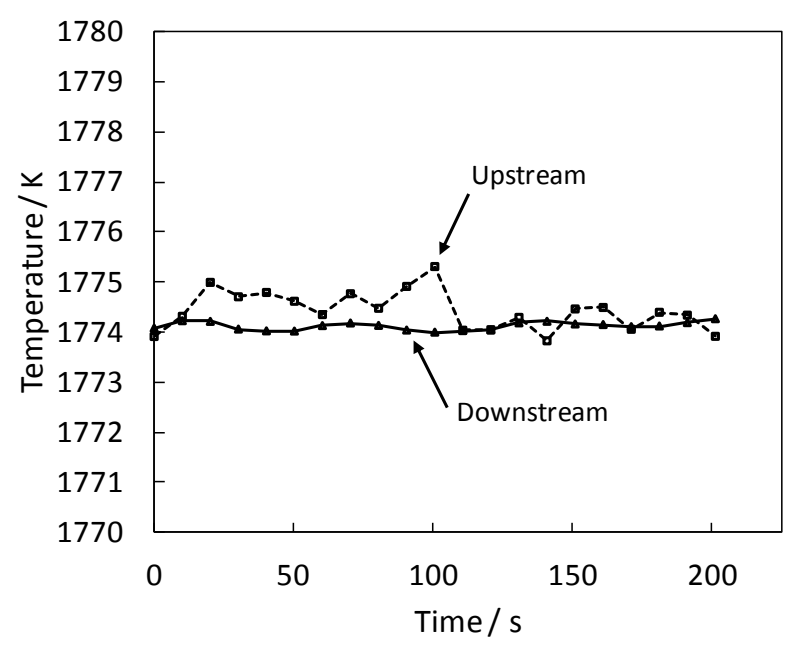

Figure 1 Temperature at the upstream and downstream

bed surfaces during a representative cycle

In a second set of identically timed experiments, the ceria particles were held at $1773 \mathrm{~K}$ in a flow of air. The evaluation of morphology in air as well as during temperature swing cycling was motivated by observation that the gas environment can impact the sintering behavior of ceramics (Rahaman, 2003). For the ceria sintered in air, the same procedure was followed as for isothermal cycling with the exception that a $1.67 \mathrm{~mL} \cdot \mathrm{s}^{-1} \cdot \mathrm{g}_{\text {ceria }}{ }^{-1}$ flow of air was utilized. The temperature of the ceria sintered in air is similar to the temperatures during reduction in nitrogen (Fig. 1).

\subsection{Temperature-swing Cycling}

For temperature-swing cycling, two experiments were conducted. In the first, new (uncycled) particles were cycled once to compare the initial loss of surface area to that observed during isothermal cycling. In the second, particles that had stabilized after 1000 isothermal cycles were evaluated over an additional sixteen temperature-swing cycles.

For all temperature-swing cycles, the particles were reduced at $1773 \mathrm{~K}$ and oxidized at $1073 \mathrm{~K}$ (see cycling conditions listed in Table 1). The cycling conditions are identical to 
those used to evaluate $\mathrm{Ce}_{0.975} \mathrm{Zr}_{0.025} \mathrm{O}_{2}$ electrospun fibers in the same facility (Gibbons et al., 2014). For each experiment, $0.72-0.84 \mathrm{~g}$ of ceria was loaded in $10 \mathrm{~mm}$ long packed bed in a $9.5 \mathrm{~mm}$ diameter alumina tube held in an IR imaging furnace (Ulvac-Riko, VHT-E44) capable of achieving rapid changes in temperature. The temperature of the ceria was measured using exposed type-B thermocouples placed at the upstream and downstream edges of the bed. The thermocouple at the downstream bed surface was used as the input for the PID controller of the furnace. The particles were heated to $1073 \mathrm{~K}$ at a rate of $20 \mathrm{~K} \cdot \mathrm{min}^{-1}$ in the oxidizing flow of $\mathrm{CO}_{2}$ in $\mathrm{N}_{2}\left(25 \% \mathrm{~mol} \mathrm{CO}_{2}\right)$, and then were held for $10 \mathrm{~min}$ at $1073 \mathrm{~K}$ to establish an initial non-stoichiometry of $4.14 \times 10^{-5}$. A cycle consisted of ramping to $1773 \mathrm{~K}$ at $100 \mathrm{~K} \cdot \mathrm{min}^{-1}$ in a $16.67 \mathrm{~mL} \cdot \mathrm{s}^{-1} \cdot \mathrm{g}_{\text {ceria }}{ }^{-1}$ reducing flow of $\mathrm{N}_{2}$, a 5 min dwell at $1773 \mathrm{~K}$, cooling to $1073 \mathrm{~K}$ at $200 \mathrm{~K} \cdot \mathrm{min}^{-1}$, initiation of a $22.22 \mathrm{~mL} \cdot \mathrm{s}^{-1} \cdot \mathrm{g}_{\text {ceria }}{ }^{-1}$ oxidizing flow of $\mathrm{CO}_{2}(25 \% \mathrm{~mol})$ and $\mathrm{N}_{2}(75 \% \mathrm{~mol})$ for a 4 min oxidation, and a 2 min purge at $1073 \mathrm{~K}$ in a $16.67 \mathrm{~mL} \cdot \mathrm{s}^{-1} \cdot \mathrm{g}_{\text {ceria }}{ }^{-1}$ flow of $\mathrm{N}_{2}$. Figure 2 shows the temperature of the upstream and downstream edges of the ceria bed during a representative temperature-swing redox cycle. After completing the desired number of cycles, the ceria was cooled to room temperature in the oxidizing flow at a rate of $20 \mathrm{~K} \cdot \mathrm{min}^{-1}$.

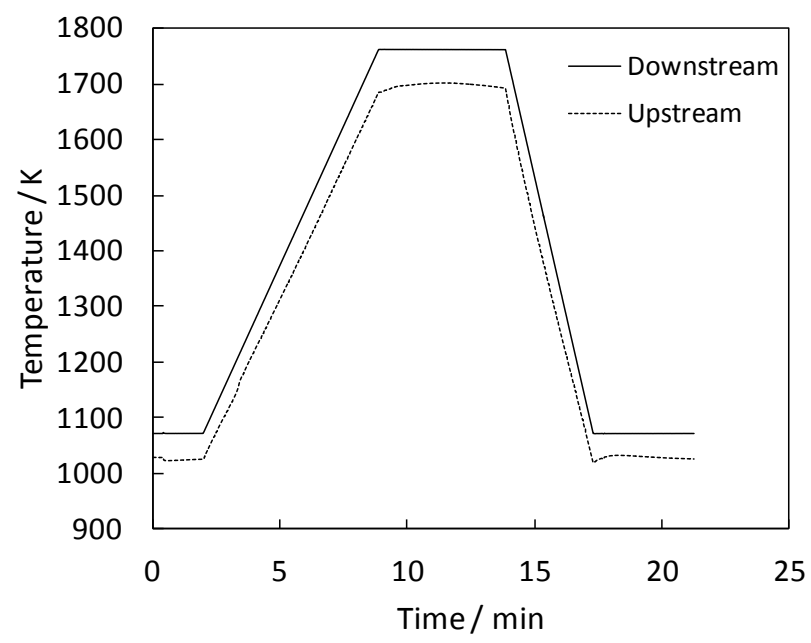

Figure 2 Temperature of the ceria bed during the temperature-swing cycling 


\subsection{Fuel Production}

In all experiments, a small reference flow of Argon $\left(1.25 \mathrm{~mL} \cdot \mathrm{s}^{-1}\right)$ was injected downstream of the furnace. A sample flow $\left(\sim 4.58 \mathrm{~mL} \cdot \mathrm{s}^{-1}\right)$ was removed from the exhaust for measurement of gas composition using both Raman laser gas analyzer (RLGA) capable of measuring $\mathrm{O}_{2}$ and $\mathrm{CO}$ volume concentrations to an absolute accuracy of $\pm 0.025 \%$, and a mass spectrometer (MS) capable of measuring $\mathrm{O}_{2}$ concentration to an absolute accuracy of $\pm 0.002 \%$. Prior to each experiment, the RLGA was calibrated using known concentrations of carbon monoxide in carbon dioxide, oxygen in nitrogen, and pure argon. The mass spectrometer was calibrated using known concentrations of oxygen in argon.

The instantaneous gas production rates, for species ' $i$ ', were determined from the RLGA data by

$\dot{\mathrm{V}}_{\mathrm{i}}=\mathrm{X}_{\mathrm{i}} \cdot \dot{\mathrm{V}}_{\text {total }}$

and from the mass spectrometer data by

$\dot{\mathrm{V}}_{\mathrm{i}}=\dot{\mathrm{V}}_{\text {ref }} \cdot \mathrm{c}_{\mathrm{i}, \text { ref }} \cdot \frac{\mathrm{I}_{\mathrm{i}}}{\mathrm{I}_{\text {ref }}}+\mathrm{b}_{\mathrm{i}, \text { ref }}$

where $c_{i, r e f}$ and $b_{i, \text { ref }}$ are calibration constants. The reported cycle-average fuel production rate is the total production averaged over the $200 \mathrm{~s}$ reduction/oxidation cycle for isothermal experiments and over the 21.5 minute cycle, excluding the 2 minute purge, for the temperature swing experiment. Both averages exclude the ten minute dwell prior to the initiation of cycling. The instantaneous and cycle average fuel production rates are normalized by the mass of ceria consistent with reports of production in the literature.

\subsection{Characterization of Morphology}

The evolution of the morphology is evaluated based on evolution of surface area, porosity, and grain size. Specific surface area before cycling and over the course of time during cycling was measured by gas adsorption via the multipoint BET method with Krypton as the absorbate. The samples were degassed at $473 \mathrm{~K}$ for three hours prior to the 
measurement. Adsorption measurements were conducted at $77.3 \mathrm{~K}$ over a relative pressure (vapor/saturation pressure) range of 0.01 to 0.3 . The measurement uncertainty is $\pm 10 \%$ of the reading.

To characterize the grain size and fiber diameter and length, scanning electron microscopy images were taken with a JEOL JSM 6700F or a Hitachi S-4700 SEM with a $5 \mathrm{kV}$ accelerating voltage. The samples were prepared with a $75 \AA \mathrm{Pt}$ coating. The images were analyzed using imageJ software to measure the fiber diameter, length, and grain size along the axis of the fiber. The fiber length and diameter measurements were conducted at 200 and 500 magnification, respectively. Sixty-seven fibers were measured for length and 76 for diameter. The grain size was measured at 1000 magnification and at least 50 grains were measured. To determine if the grain size distributions of the separate experiments are statistically different and to calculate the corresponding p-value, the non-parametric, two sample Kolmogorov-Smirnov (KS) test was applied (Young, 1977).

The initial porosity of the particles was determined via mercury intrusion. After each test, the porosity was calculated based on measured dimensions and mass (Sartorius GD 503 mass balance $( \pm 0.0002 \mathrm{~g}))$ using a bulk density of $7.22 \mathrm{~g} \cdot \mathrm{cm}^{-3}$ (JCPDS - International Centre for Diffraction Data, 1993). For the particles characterized prior to cycling, the porosity calculated using this method, $77.5 \%$, agrees with porosity measured via mercury intrusion, 77.8\%. All uncertainties are for the $95 \%$ percentile.

\section{RESULTS}

\subsection{New Particle Morphology}

The new particles comprised randomly oriented fibers with limited entanglement resulting in a non-woven appearance (Figure 3a,b). The mean fiber diameter and length were $6.2 \pm 0.4 \mu \mathrm{m}$ and $47 \pm 10 \mu \mathrm{m}$. The average grain size along the fiber axis was $3.7 \pm 0.41 \mu \mathrm{m}$. 
The mean particle length and diameter were $4.82 \pm 0.09 \mathrm{~mm}$ and $4.84 \pm 0.05 \mathrm{~mm}$. The particles were $77.5 \pm 1.7 \%$ porous with specific surface area of $0.143 \mathrm{~m}^{2} \cdot \mathrm{g}^{-1}$.

\subsection{Isothermal Cycling}

SEM images of the particles before cycling and during isothermal cycling are shown in Figure 3. The SEM images over the course of cycling show the impact of sintering. Figures 3c-f show a thickening of the fibers, neck growth between fibers, and increase in grain size, similar to the behavior of electrospun fibers (Gibbons et al., 2014). A stable configuration is reached at 500 cycles (Figure 3f) and maintained through 1000 cycles (Figure 3g,h). The nonwoven fibers maintain separation and retain an open porous structure.

Figure 4 shows the evolution of specific surface area. Over the first cycle $(0.056 \mathrm{hr})$, $23 \%$ of the surface area was lost but changes in porosity and grain size (Figures 5 and 6) were not measurable. Venstrom, et al. observed a similar initial decrease in surface area of decomposition synthesized ceria (Venstrom et al., 2012). Over cycles 2 to 25 (0.056 to $1.39 \mathrm{hr}$ ) the average grain size increased statistically significantly from $4 \mu \mathrm{m}$ to $5 \mu \mathrm{m}$ (pvalue $=0.01$, but additional surface area was not lost. Consistent with the observation that grain growth can reinitiate sintering by perturbing the balance between grain boundary and surface area energies (Kellett and Lange, 1989; Lange and Kellett, 1989; Lange, 2008; Zhang et al., 2002), surface area loss was reinitiated during cycle 26. Although some of the cycle-tocycle changes in surface area are within the instrument uncertainty, there is a consistent trend of decreasing surface area in the data. Surface area stabilized at $\sim 0.08 \mathrm{~m}^{2} \cdot \mathrm{g}^{-1}$ during cycle 300 (16.67 hr). Grain growth continued until 500 cycles $(27.78 \mathrm{hr})$. The stabilized particles are $73 \pm 1.5 \%$ porous with a surface area of $0.078 \mathrm{~m}^{2} \cdot \mathrm{g}^{-1}$ and an average grain size of $8.2 \pm 1.6 \mu \mathrm{m}$ 

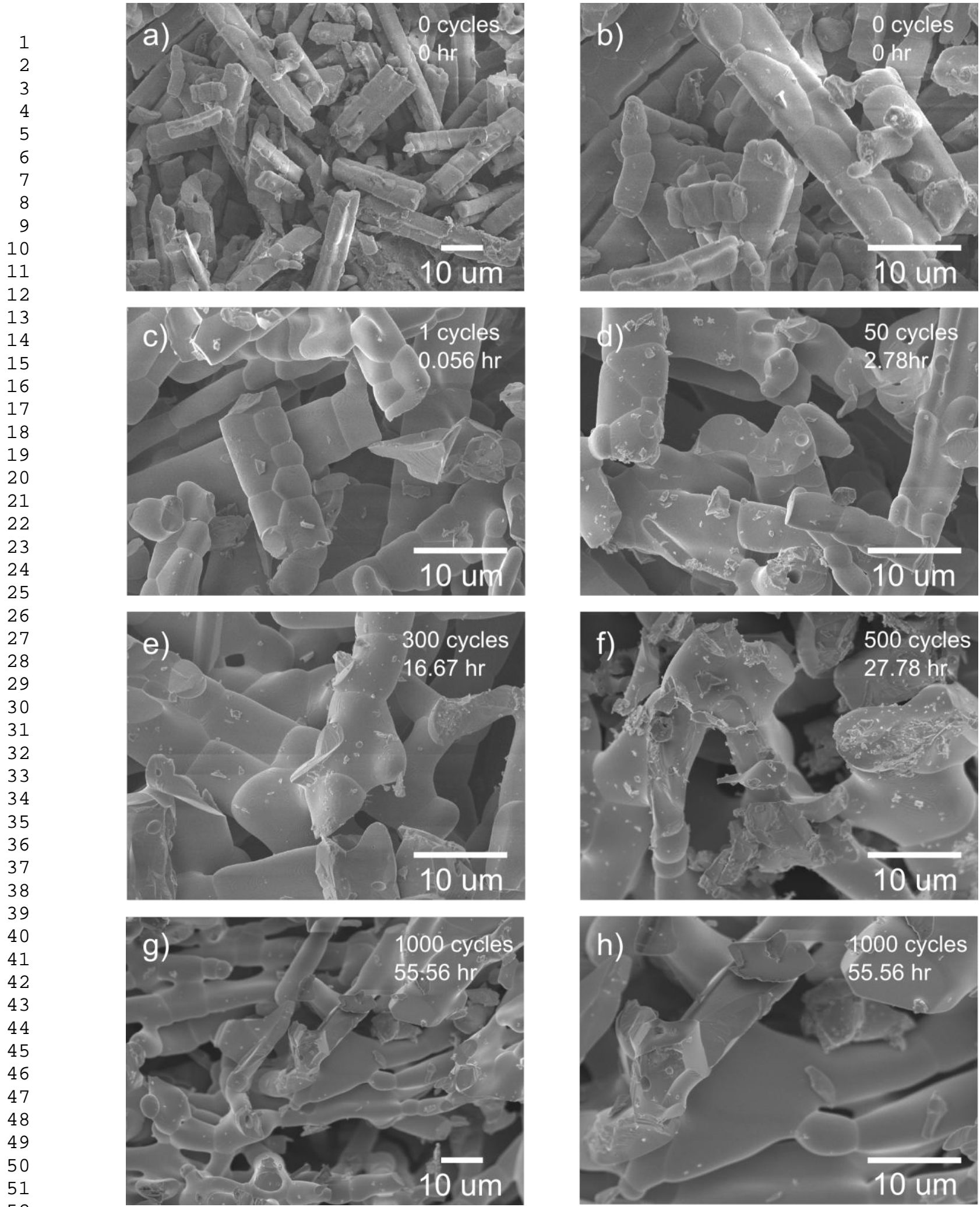

Figure 3 SEM images of the ceria fiber particles over the course of isothermal cycling (2000x unless noted): (a) as manufactured (new) at 1000x, (b) as manufactured, (c) 1 cycle (0.056 hr), (d) 50 cycles $(2.78 \mathrm{hr}),(\mathrm{e}) 300$ cycles $(16.67 \mathrm{hr}),(\mathrm{f}) 500$ cycles $(27.78 \mathrm{hr}),(\mathrm{g}) 1000$ cycles $(55.56 \mathrm{hr})$ at $1000 \mathrm{x},(\mathrm{h})$ 1000 cycles $(55.56 \mathrm{hr})$ 


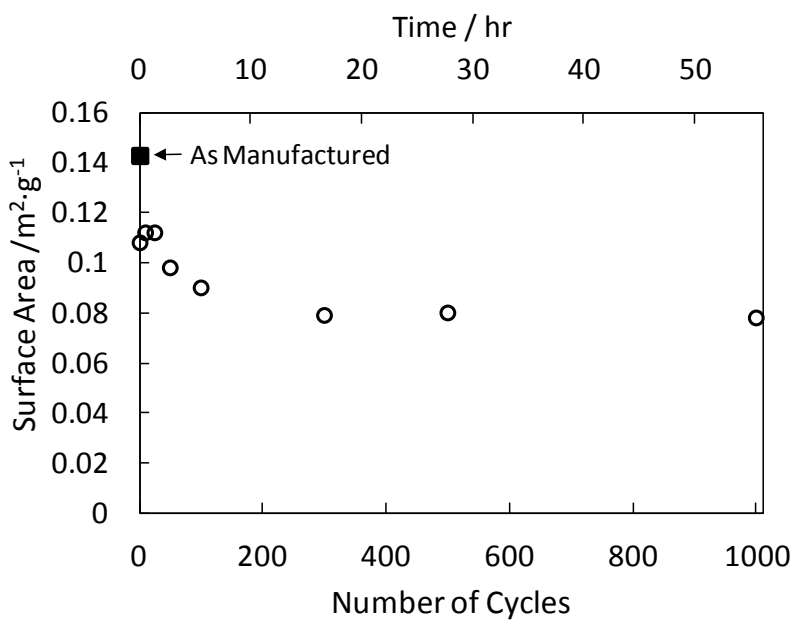

Figure 4 Specific surface area as a function of isothermal cycle number and time. Measured via gas absorption via the multipoint BET method.

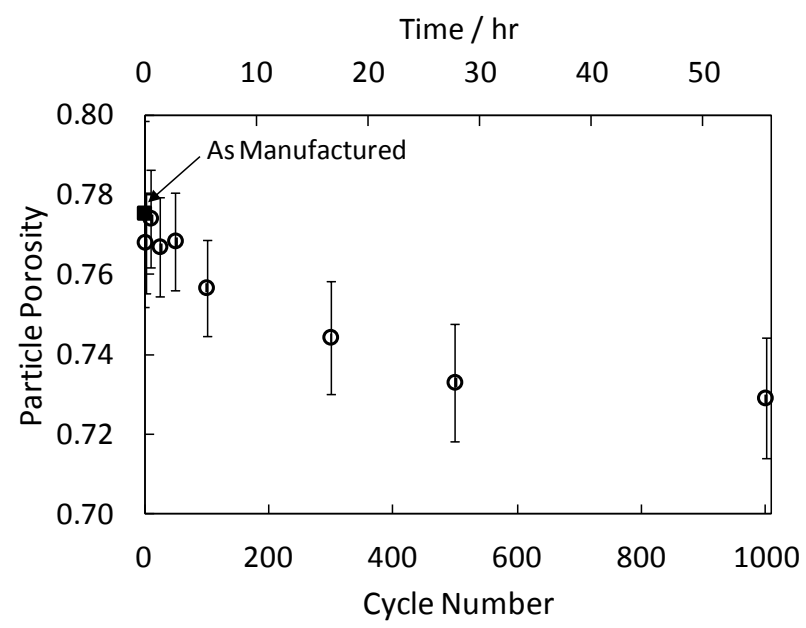

Figure 5 Particle porosity as a function of isothermal cycle number and time. Determined based on measured dimensions and mass.

The evolution of the morphology of particles heated in air is similar to that observed during isothermal cycling. After $55.56 \mathrm{hr}$ in air at $1773 \mathrm{~K}$, the surface area was $0.078 \mathrm{~m}^{2} \cdot \mathrm{g}^{-1}$, the mean grain size was $8.2 \pm 1.8 \mu \mathrm{m}$, and the porosity was $72.6 \pm 1.5 \%$.

Figure 7 shows the cycle-average $\mathrm{CO}$ and $\mathrm{O}_{2}$ production rates. The average fuel production rate is the performance metric most relevant to the efficiency of the process. At 


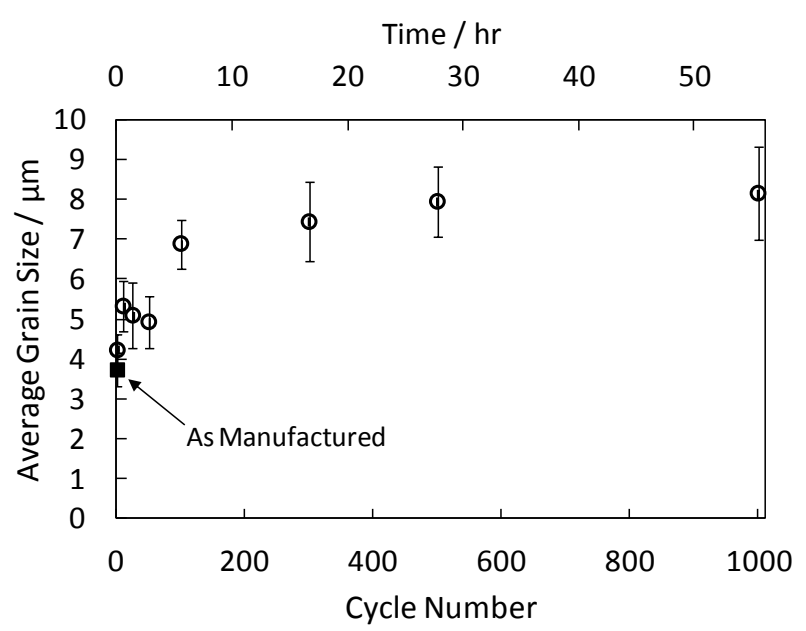

Figure 6 Average grain size as a function of time and isothermal cycle number. Determined via analysis of SEM images.

equilibrium, pure ceria regardless of morphology will produce the same total amount of fuel for identical swings in temperatures and oxygen activities. Thus for the same material composition, the rate of fuel production per cycle provides the most meaningful comparison of morphologies cycled at the same temperatures, partial pressure of $\mathrm{O}_{2}$, and cycle duration. Ceria based materials have been shown to be thermodynamically rather than kinetically limited under high-temperature reduction and for isothermal cycling. The highest fuel productivity occurs in the limit of an infinitesimally short cycle time (Davenport et al., 2016). Thus as shown by Venstrom et al., short cycles, of about 200s for practical reasons, with high rates of release of oxygen and production of $\mathrm{CO}$, yield the highest solar to fuel efficiency (Venstrom et al., 2014).

The specific surface area is overlaid on the plot to illustrate the impact of surface area on fuel production. The cyclic change in non-stoichiometry was $\Delta \delta=0.0028$, corresponding to cycle-average CO production of $2.04 \pm 0.03 \mu \mathrm{L} \cdot \mathrm{s}^{-1} \cdot \mathrm{g}^{-1}$ over the first 50 cycles $(2.78 \mathrm{hr})$. The CO production decreased from cycle 50 to cycle $300(16.67 \mathrm{hr})$ to $1.82 \pm 0.03 \mu \mathrm{L} \cdot \mathrm{s}^{-1} \cdot \mathrm{g}^{-1}$ 


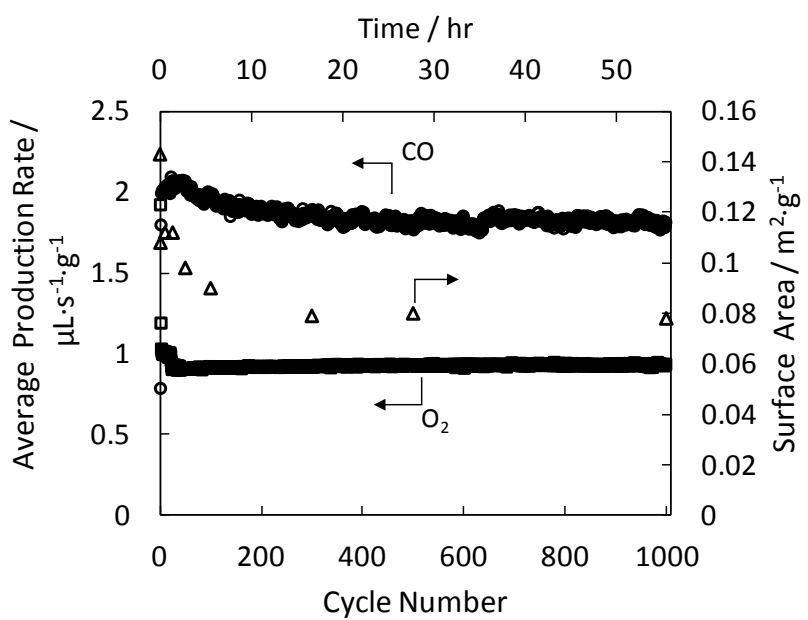

Figure 7 Cycle averaged rates of $\mathrm{CO}(\mathrm{o})$ and $\mathrm{O} 2(\square)$ production, measured via RLGA and mass spectroscopy, respectively, and surface area $(\Delta)$ versus isothermal cycle number.

$(\Delta \delta=0.0025)$. The $11 \%$ decrease in CO production corresponds to a $27 \%$ loss in surface area from $0.11 \mathrm{~m}^{2} \cdot \mathrm{g}^{-1}$ to $0.08 \mathrm{~m}^{-2} \cdot \mathrm{g}^{-1}$. Over the next 700 cycles, fuel production and specific surface area remained stable. The instantaneous rates were also stable over the final 700 cycles, peaking at $5 \mu \mathrm{L} \cdot \mathrm{s}^{-1} \cdot \mathrm{g}^{-1}$ at the initiation of oxidation and decreasing to $3 \mu \mathrm{L} \cdot \mathrm{s}^{-1} \cdot \mathrm{g}^{-1}$ at $100 \mathrm{~s}$. The high retention of fuel production despite a loss of surface area is consistent with the observation in prior work (Davenport et al., 2016; Venstrom et al., 2014) that fuel production is limited by thermodymanics rather than kinetics. Thus the particles are suitable for isothermal cycling under the conditions that yield the highest solar to fuel efficiency for this mode of operation.

Though differences in flow rate and cycle duration restrict the comparison to a qualitative one, the average rate of CO production is similar to the rate $\left(1.96 \mu \mathrm{L} \cdot \mathrm{s}^{-1} \cdot \mathrm{g}^{-1}\right)$ for isothermal cycling of a porous monolith with initial porosity of $65 \%$ and a surface area of 0.1 $\mathrm{m}^{2} \cdot \mathrm{g}^{-1}$ (Venstrom et al., 2014). If the ceria had been cycled between equilibrium with $10 \mathrm{ppm}$ 
$\mathrm{O}_{2}$ in $\mathrm{N}_{2}$ and pure $\mathrm{CO}_{2}$ at $1773 \mathrm{~K}$, the total fuel production would be $5.6 \mathrm{~mL} \cdot \mathrm{g}^{-1}$

$(\Delta \delta=0.0389)$. However, the average rate would be much slower and thus, as previously

noted, shorter cycles that do not reach equilibrium yield higher efficiency (Davenport et al., 2016; Hathaway et al., 2015; Rhodes et al., 2015; Venstrom et al., 2015, 2014).

\subsection{Temperature-Swing Cycling}

Figure 8 shows SEM images obtained at the end of the first temperature-swing cycle $(0.36 \mathrm{hr})$ for new, as manufactured, particles. Qualitatively, the overall appearance of the cycled particle is very similar to a new particle at 1000 magnification (compare 8a to 3a). Grain growth is evident in the higher magnification image (compare $8 b$ to $3 b$ ). The surface area decreased from 0.143 to $0.093 \mathrm{~m}^{2} \cdot \mathrm{g}^{-1}$ and the mean grain size increased significantly ( $\mathrm{p}$ value $=0.0007)$ from $3.7 \pm 0.41 \mu \mathrm{m}$ to $5.1 \pm 1.3 \mu \mathrm{m}$. The porosity, $77 \pm 1.3 \%$, did not change.
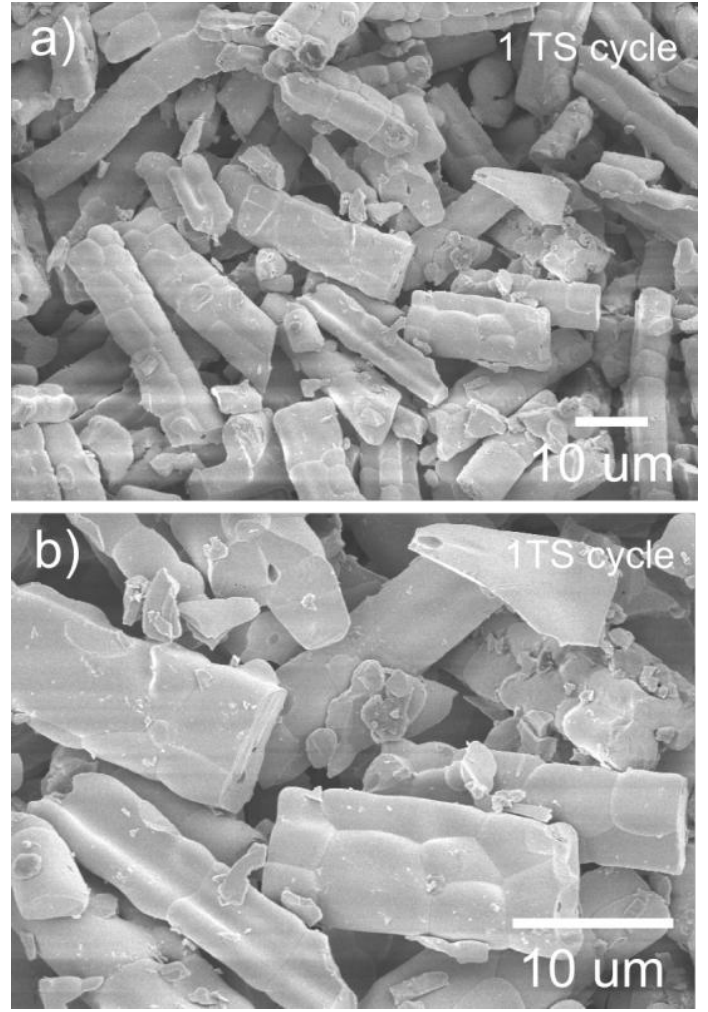

Figure 8 SEM images, at (a) 1000x and (b) 2000x magnification, of the ceria after one temperature-swing cycle. 
To reach a similar specific surface area required 5.56 hours during isothermal cycling. For comparison, the electrospun fibers had a surface area of $0.28 \mathrm{~m}^{2} \cdot \mathrm{g}^{-1}$ after ten temperature swing cycles between $1773 \mathrm{~K}$ and $1073 \mathrm{~K}$ (Gibbons et al., 2014).

The CO production is compared to data for electrospun fibers (Gibbons et al., 2014) in Figure 9. The peak rate for the particles used in the present study is $680 \mu \mathrm{L} \cdot \mathrm{s}^{-1} \cdot \mathrm{g}^{-1}$ compared to $525 \mu \mathrm{L} \cdot \mathrm{s}^{-1} \cdot \mathrm{g}^{-1}$ for the electrospun fibers. Consistent with prior studies (Gibbons et al., 2014; Scheffe et al., 2013), the low level of Zr doping of the electrospun fibers increased the extent of reduction (based on total fuel production) but increased the time to reoxidize. The cycle-averaged rate of CO production for the particles is $4.96 \mu \mathrm{L} \cdot \mathrm{s}^{-1} \cdot \mathrm{g}^{-1}$ compared to $5.94 \mu \mathrm{L} \cdot \mathrm{s}^{-1} \cdot \mathrm{g}^{-1}$ for electrospun fibers.

Images of the particles at the end of second experiment (in which the particles isothermally cycled are cycled with a temperature swing) are shown in Figure 10. Though the appearance is similar to the particles after isothermal cycling (Figure 3g,h), the surface area

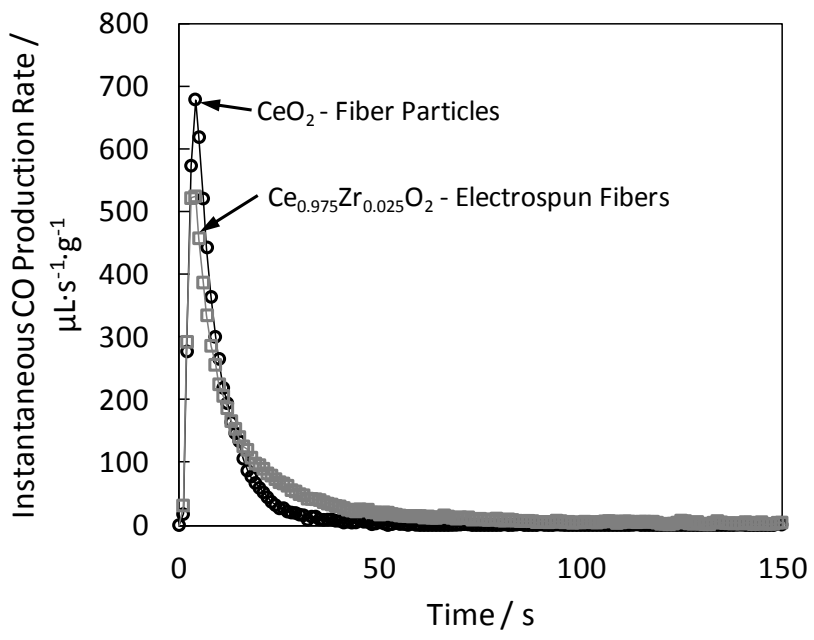

Figure 9 Instantaneous $\mathrm{CO}$ production rate for the first temperature-swing cycle of the ceria particles and for the $\mathrm{Ce}_{0.975} \mathrm{Zr}_{0.025} \mathrm{O}_{2}$ electrospun fibers (Gibbons et al., 2014) versus oxidation time. 
after 16 temperature-swing cycles is reduced from $0.078 \mathrm{~m}^{2} \cdot \mathrm{g}^{-1}$ to $0.057 \mathrm{~m}^{2} \cdot \mathrm{g}^{-1}$. The final surface area equals that of dual-scale porosity RPC ceria after $120 \mathrm{hr}$ at $1773 \mathrm{~K}$ in air (Furler et al., 2014). The grain size $(8.7 \pm 1.6 \mu \mathrm{m})$ and particle porosity $(72 \pm 1.7 \%)$ did not change. Although, the data do not provide sufficient information to identify the underlying mechanisms for additional surface loss during temperature-swing cycling after isothermal cycling, the larger change in non-stoichiometry ( $\Delta \delta \approx 0.04$ vs 0.0025$)$ is a possibility. The larger swing in non-stoichiometry can speed sintering by decreasing the number of oxygen vacancies (Djurovic et al., 2007) and by more rapid diffusion of oxygen in the lattice (Inaba et al., 1998). Gradients in non-stoichiometry and temperature can also create strain due to differential expansion within the particles (Bishop et al., 2009).

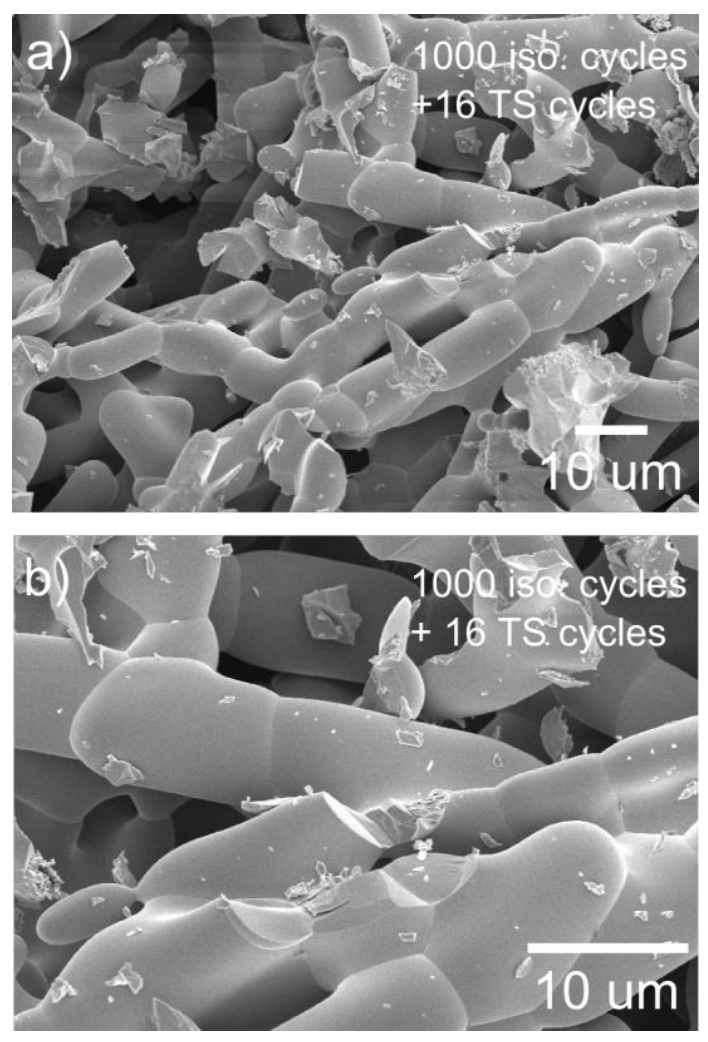

Figure 10 SEM images, at (a) 1000x and (b) 2000x magnification, of the ceria after 1000 isothermal cycles and sixteen additional temperature-swing cycles 
Figure 11 shows the cycle-average $\mathrm{CO}$ and $\mathrm{O}_{2}$ production rates versus cycle number

(11a) and the transient $\mathrm{CO}$ production rate (11b). The first cycle is not shown in Figure 11a because the reduction temperature was $15 \mathrm{~K}$ less than subsequent cycles. The cycle-average CO production averaged over the 15 cycles is $4.8 \pm 0.12 \mu \mathrm{L} \cdot \mathrm{s}^{-1} \cdot \mathrm{g}^{-1}$. There is a slight increase in average $\mathrm{CO}$ production rate over the last 7 cycles due to a 5 degree increase in reduction temperature. Faster cycle-average rates could be obtained by using shorter cycles as indicated by shape of the curves in Figure $11 \mathrm{~b}$. At the onset of oxidizing flow $(0 \mathrm{~s})$, the peak $\mathrm{CO}$ production rate is between 130 (cycle 5) and 140 (cycle 15) $\mu \mathrm{L} \cdot \mathrm{s}^{-1} \cdot \mathrm{g}^{-1}$ and then the rate decays to $<3 \mu \mathrm{L} \cdot \mathrm{s}^{-1} \cdot \mathrm{g}^{-1}$ at $180 \mathrm{~s}$. In comparison to the rate of CO production of the newly manufactured particles (Fig. 9), there is a 79\% reduction in the peak rate. The reduction in the peak instantaneous rate is attributed to the lower surface area.

These results, along with the prior work with electrospun fibers, which found that surface area decreased twofold for each $100 \mathrm{~K}$ increase in reduction temperature, point to the need for more stable morphologies with higher surface area to take full advantage of the more favorable thermodynamics associated with reduction at $1773 \mathrm{~K}$. Potentially, for the current fibrous particles, it would be preferable to eliminate the high temperature firing during manufacture to preserve surface area and then cycle at a lower reduction temperature. This suggestion is consistent with the recommendation of Gibbons, et al (Gibbons et al., 2014) to use a reduction temperature of $1673 \mathrm{~K}$ rather than $1773 \mathrm{~K}$. 

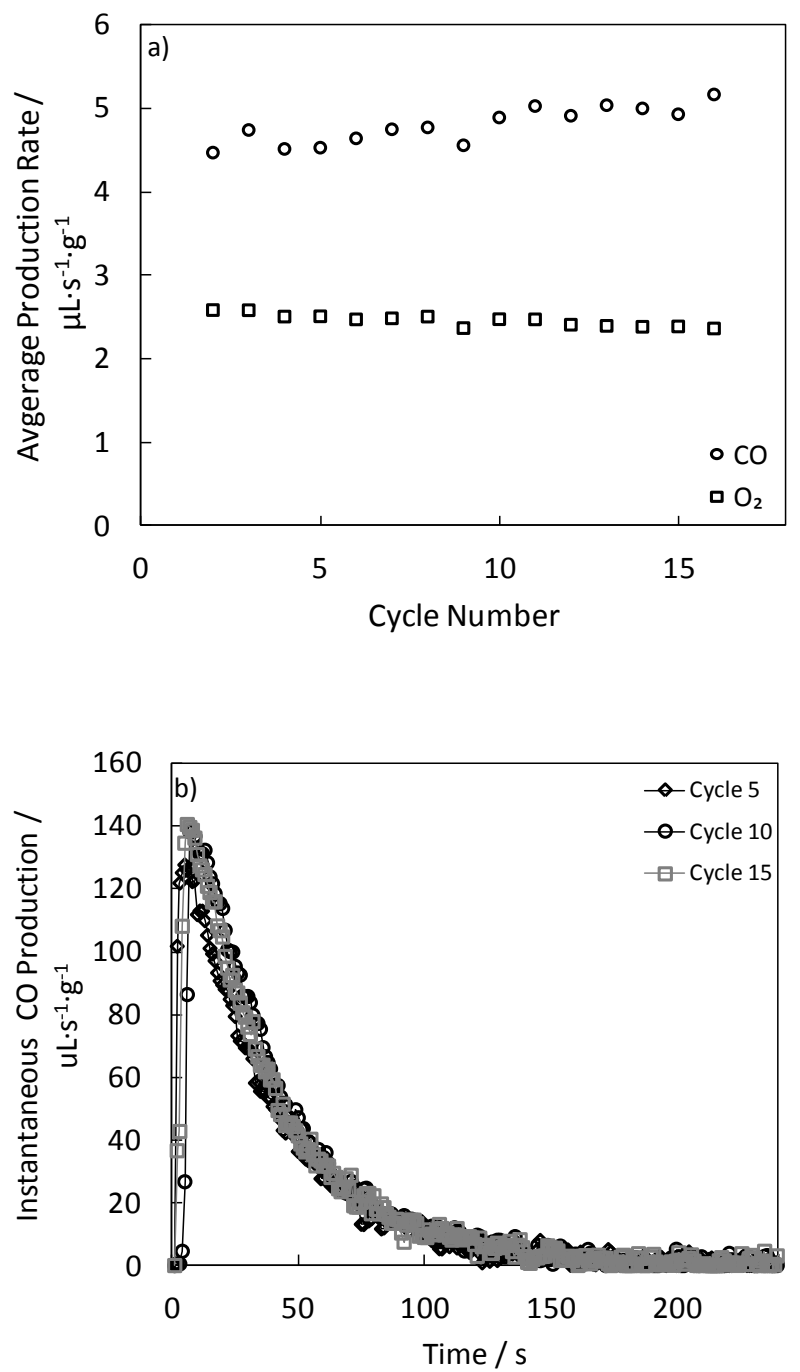

Figure 11 The (a) cycle-average and (b) instantaneous rate of $\mathrm{CO}$ production for the temperature-swing cycles of the ceria that had been cycled isothermally 1000 times.

\section{CONCLUSION}

In this study, we consider the sintering and fuel production behavior of porous ceria particles over thousands of thermochemical metal redox cycles. The particles comprise micron-sized ceria fibers that are randomly orientated, with limited entanglement. The particles were fabricated in a process amenable to mass production. The transient behavior 
was examined for both isothermal and temperature-swing cycling. For isothermal redox cycling at $1773 \mathrm{~K}$ at the conditions that yield the highest solar-to-fuel efficiency, the cyclic change in non-stoichiometry $(\Delta \delta)$ was 0.0025 . Over 56 hours (1000 cycles), the particles retained an open, porous microstructure (initial porosity $=78 \%$; final $=73 \%$ ). The specific surface area stablized in 17 hours after 300 cycles at $56 \%$ of the initial specific surface area (initial $=0.143 \mathrm{~m}^{2} \cdot \mathrm{g}^{-1}$; final $=0.078 \mathrm{~m}^{2} \cdot \mathrm{g}^{-1}$ ). About half of the loss in surface area occurred over the first cycle $(0.056 \mathrm{hr})$. Heating in air yielded the same morphology. The particles retained $89 \%$ of the peak fuel production with a stable, average fuel production rate of $1.82 \mu \mathrm{L} \cdot \mathrm{s}^{-1} \cdot \mathrm{g}^{-1}$ over the last 700 cycles. Despite the low surface area, the fiber particles are suitable for isothermal cycling because, as shown in prior work, fuel production is limited by the thermodynamic capacity of the sweep gas rather than by surface kinetics (Davenport et al., 2016; Venstrom et al., 2014). Fuel production is similar to pressed monolith particles evaluated for isothermal cycling.

For temperature-swing cycling between $1773 \mathrm{~K}$ and $1073 \mathrm{~K}$, the cyclic change in nonstoichiometry was 0.04 . The particles that had reached a stable morphology after 1000 isothermal cycles, lost $29 \%$ more surface area $\left(0.057 \mathrm{~m}^{2} \cdot \mathrm{g}^{-1}\right)$ yet retained an open, porous microstructure. Even though the advantage of higher fuel production with temperature-swing cycling was significant with the more dense material, a higher surface area morphology is preferred. Potentially, it would be beneficial to eliminate the high temperature firing during manufacture to preserve surface area and then cycle at a lower reduction temperature. This suggestion is consistent with the prior work on electrospun fibers for which fuel production was higher at $1673 \mathrm{~K}$ that at $1773 \mathrm{~K}$ (Gibbons et al., 2014), even with $\mathrm{Zr}$ doping to stabilize the morphology. Future efforts to increase the stable surface area through fiber selection and the addition of low levels of $\mathrm{Zr}$ doping are recommended. 
The mass-produced fibrous structures have adequately stable morphologies to produce fuel production performance similar to less scalable (developed in a laboratory setting) structures with similar pre-cycling surface area. The fiber structures evaluated are mm-sized particles intended for use in a fixed bed solar reactor. The manufacturing technique can be applied to produce larger structures for different reactor types. Design of larger structures must consider the impact of transport processes and mechanical integrity under the intended operating conditions. 


\section{ACKNOWLEDGEMENTS}

The authors thank Dr. Peter Krenzke and Stephen Sedler for the SEM images shown in Figs. 3. The ceria particles were supplied by Zircar Zirconia, Inc. We appreciate their help in exploring methods to control particle morphology.

The financial support by the U.S. Department of Energy's Advanced Research Projects Agency-Energy (DOE ARPA-E, award no. DE-AR0000182) to the University of Minnesota, and by the University of Minnesota Initiative for Renewable Energy and the Environment (IREE, grant no. RM-0001-12) is gratefully acknowledged.

The information, data, or work presented herein was funded in part by an agency of the United States Government. Neither the United States Government nor any agency thereof, nor any of their employees, makes any warranty, express or implied, or assumes any legal liability or responsibility for the accuracy, completeness, or usefulness of any information, apparatus, product, or process disclosed, or represents that its use would not infringe privately owned rights. Reference herein to any specific commercial product, process, or service by trade name, trademark, manufacturer, or otherwise does not necessarily constitute or imply its endorsement, recommendation, or favoring by the United States Government or any agency thereof. The views and opinions of authors expressed herein do not necessarily state or reflect those of the United States Government or any agency thereof.

\section{NOMECLATURE}

\begin{tabular}{lll}
\hline Symbol & Description & Unit \\
\hline $\mathrm{b}_{\mathrm{i}, \text { ref }} \mathrm{c}_{\mathrm{i}, \text { ref }}$ & Mass spectrometer calibration constants &
\end{tabular}




$\begin{array}{lll}\mathrm{I}_{\mathrm{i}} & \text { Mass spectrometer signal for species ' } \mathrm{i} \text { ' } & \mathrm{A} \\ \mathrm{T}_{\mathrm{ox}} & \text { Oxidation temperature } & \mathrm{K} \\ \mathrm{T}_{\mathrm{rd}} & \text { Reduction temperature } & \mathrm{K} \\ \dot{\mathrm{V}}_{\mathrm{ox}}^{\prime} & \text { Oxidizer mass specific, volumetric flow rate } & \mathrm{mL} \cdot \mathrm{s}^{-1} \cdot \mathrm{g}^{-1} \\ \dot{\mathrm{V}}_{\mathrm{rd}}^{\prime} & \text { Reduction gas mass specific, volumetric flow rate } & \mathrm{mL} \cdot \mathrm{s}^{-1} \cdot \mathrm{g}^{-1} \\ \dot{\mathrm{V}}_{\text {ref }} & \text { Reference (Argon) volumetric flow rate } & \mathrm{mL} \cdot \mathrm{s}^{-1} \\ \mathrm{X}_{\mathrm{i}} & \text { Mole fraction of species ' } \mathrm{i} \text { ' } & \\ \Delta \delta & \text { change in non-stoichiometry } & - \\ \tau_{\mathrm{ox}} & \text { Oxidation half cycle time } & \mathrm{sec} \\ \tau_{\text {purge }} & \text { Purge time } & \mathrm{sec} \\ \tau_{\mathrm{rd}} & \text { Reduction half cycle time } & \mathrm{sec}\end{array}$

\section{REFERENCES}

Ackermann, S., Scheffe, J.R., Steinfeld, A., 2014. Diffusion of oxygen in ceria at elevated temperatures and its application to $\mathrm{H} 2 \mathrm{O} / \mathrm{CO} 2$ splitting thermochemical redox cycles. J. Phys. Chem. C 118, 5216-5225. doi:10.1021/jp500755t

Bader, R., Bala Chandran, R., Venstrom, L.J., Sedler, S.J., Krenzke, P.T., De Smith, R.M., Banerjee, A., Chase, T.R., Davidson, J.H., Lipiński, W., 2015. Design of a Solar Reactor to Split CO 2 Via Isothermal Redox Cycling of Ceria. J. Sol. Energy Eng. 137, 031007. doi:10.1115/1.4028917

Bala Chandran, R., De Smith, R.M., Davidson, J.H., 2015. Model of an integrated solar thermochemical reactor/reticulated ceramic foam heat exchanger for gas-phase heat recovery. Int. J. Heat Mass Transf. 81, 404-414. doi:10.1016/j.ijheatmasstransfer.2014.10.053

Bishop, S.R., Duncan, K.L., Wachsman, E.D., 2009. Defect equilibria and chemical expansion in non-stoichiometric undoped and gadolinium-doped cerium oxide. Electrochim. Acta 54, 1436-1443. doi:10.1016/j.electacta.2008.09.026

Brendelberger, S., Roeb, M., Lange, M., Sattler, C., 2015. Counter flow sweep gas demand for the ceria redox cycle. Sol. Energy 122, 1011-1022. doi:10.1016/j.solener.2015.10.036

Bulfin, B., Call, F., Lange, M., Lübben, O., Sattler, C., Pitz-Paal, R., Shvets, I. V., 2015. Thermodynamics of $\mathrm{CeO} 2$ thermochemical fuel production. Energy and Fuels 29, 1001- 
1009. doi:10.1021/ef5019912

Chandran, R.B., Davidson, J.H., 2016. Model of Transport and Chemical Kinetics in a Solar Thermochemical Reactor To Split Carbon Dioxide. Chem. Eng. Sci. 146, 302-315. doi:10.1016/j.ces.2016.03.001

Chueh, W.C., Abbott, M., Scipio, D., Haile, S.M., 2010. High-flux solar-driven thermochemical dissociation of $\mathrm{CO} 2$ and $\mathrm{H} 2 \mathrm{O}$ using ceria redox reactions. Science. 330, 1797-1801. doi:10.1123/science.1197834

Chueh, W.C., Haile, S.M., 2010. A thermochemical study of ceria: exploiting an old material for new modes of energy conversion and CO2 mitigation. Philos. Trans. A. Math. Phys. Eng. Sci. 368, 3269-3294. doi:10.1098/rsta.2010.0114

Davenport, T.C., Yang, C., Kucharczyk, C.J., Ignatowich, M.J., Haile, S.M., 2016. Implications of Exceptional Material Kinetics on Thermochemical Fuel Production Rates 1-8. doi:10.1002/ente.201500506

Djurovic, D., Zinkevich, M., Boskovic, S., Strot, B., Aldinger, F., 2007. Densification Behaviour of Nano-Sized CeO2. Mater. Sci. Forum 555, 189-194.

Ermanoski, I., Miller, J.E., Allendorf, M.D., 2014. Efficiency maximization in solarthermochemical fuel production: challenging the concept of isothermal water splitting. Phys. Chem. Chem. Phys. 16, 8418-8427. doi:10.1039/c4cp00978a

Eyring, L., 1991. The Binary Lanthanide Oxides: Synthesis and Identification. Synth. Lanthan. Actin. Compd. 2, 187-224. doi:10.1007/978-94-011-3758-4_8

Furler, P., Scheffe, J., Gorbar, M., Moes, L., Vogt, U., Steinfeld, A., 2012a. Solar thermochemical $\mathrm{CO} 2$ splitting utilizing a reticulated porous ceria redox system. Energy \& Fuels 26, 7051-7059. doi:10.1021/ef3013757

Furler, P., Scheffe, J., Marxer, D., Gorbar, M., Bonk, A., Vogt, U., Steinfeld, A., 2014. Thermochemical $\mathrm{CO} 2$ splitting via redox cycling of ceria reticulated foam structures with dual-scale porosities. Phys. Chem. Chem. Phys. 16, 10503-11. doi: $10.1039 / \mathrm{c} 4 \mathrm{cp} 01172 \mathrm{~d}$

Furler, P., Scheffe, J.R., Steinfeld, A., 2012b. Syngas production by simultaneous splitting of $\mathrm{H} 2 \mathrm{O}$ and $\mathrm{CO} 2$ via ceria redox reactions in a high-temperature solar reactor. Energy Environ. Sci. 5, 6098. doi:10.1039/c1ee02620h

Gibbons, W.T., Venstrom, L.J., De Smith, R.M., Davidson, J.H., Jackson, G.S., 2014. Ceriabased electrospun fibers for renewable fuel production via two-step thermal redox cycles for carbon dioxide splitting. Phys. Chem. Chem. Phys. 16, 14271-14280. doi:10.1039/c4cp01974a

Hao, Y., Yang, C.-K., Haile, S.M., 2013. High-temperature isothermal chemical cycling for solar-driven fuel production. Phys. Chem. Chem. Phys. 15, 17084. doi:10.1039/c3cp53270d

Hathaway, B.J., Bala Chandran, R., Gladen, A.C., Chase, T.R., Davidson, J.H., 2016. Demonstration of a Solar Reactor for Carbon Dioxide Splitting via the Isothermal Ceria Redox Cycle and Practical Implications. Energy and Fuels 30, 6654-6661. doi:10.1021/acs.energyfuels.6b01265

Hathaway, B.J., Bala Chandran, R., Sedler, S.J., Thomas, D., Gladen, A.C., Chase, T.R., Davidson, J.H., 2015. Effect of Flow Rates on Operation of a Solar Thermochemical 
Reactor for Splitting CO2 via the Isothermal Ceria Redox Cycle. J. Sol. Energy Eng. 138, 011007.

Inaba, H., Nakajima, T., Tagawa, H., 1998. Sintering behaviors of ceria and gadolinia-doped ceria. Solid State Ionics 106, 263-268. doi:10.1016/S0167-2738(97)00496-7

Jarrett, C., Chueh, W., Yuan, C., Kawajiri, Y., Sandhage, K.H., Henry, A., 2016. Critical limitations on the efficiency of two-step thermochemical cycles. Sol. Energy 123, 57-73. doi:10.1016/j.solener.2015.09.036

JCPDS - International Centre for Diffraction Data, 1993. Sets 43: Powder Diffraction File Inorganic and Organic, in: McMurdie, H.F. (Ed.), Sets 43: Powder Diffraction File Inorganic and Organic. p. 394.

Kellett, B.J., Lange, F.F., 1989. Thermodynamics of Densification: I, Sintering of Simple Particle Arrays, Equilibrium Congifuration, Pore Stability, and Shrinkage. J. Am. Ceram. Soc. 72, 725-734.

Krenzke, P.T., Davidson, J.H., 2015. On the Efficiency of Solar H\n $2 \backslash n$ and CO Production via the Thermochemical Cerium Oxide Redox Cycle: The Option of Inert-Swept Reduction. Energy \& Fuels 29, 1045-1054. doi:10.1021/ef502601f

Lange, F.F., 2008. Densification of powder compacts: An unfinished story. J. Eur. Ceram. Soc. 28, 1509-1516. doi:10.1016/j.jeurceramsoc.2007.12.016

Lange, F.F., Kellett, B.J., 1989. Thermodynamics of Densification: II, Grain Growth in Porous Compacts and Relation to Densification. J. Am. Ceram. Soc. 72, 735-741.

Malonzo, C.D., Smith, R.M. De, Rudisill, S.G., Petkovich, N.D., Davidson, J.H., Stein, A., 2014. Wood-Templated CeO2 as Active Material for Thermochemical CO Production. J. Phys. Chem. C 118, 26172-26181. doi:10.1021/jp5083449

Millot, F., Mierry, P.D., 1985. A new method for the study of chemical diffusion in oxides with application to cerium oxide CeO2-x. J. Phys. Chem. Solids 46, 797-801. doi:10.1016/0022-3697(85)90003-4

Panlener, R.J., Blumenthal, R.N., Garnier, J.E., 1975. A thermodynamic study of nonstoichiometric cerium dioxide. J. Phys. Chem. Solids 36, 1213-1222. doi:10.1016/0022-3697(75)90192-4

Rahaman, M.N., 2003. Densification Process Variables and Densification Practice, in: Ceramic Processing and Sintering. Marcel Dekker, Inc., New York, NY, pp. 779-845.

Rhodes, N.R., Bobek, M.M., Allen, K.M., Hahn, D.W., 2015. Investigation of long term reactive stability of ceria for use in solar thermochemical cycles. Energy 89, 1-8. doi:10.1016/j.energy.2015.06.041

Rudisill, S.G., Venstrom, L.J., Petkovich, N.D., Quan, T., Hein, N., Boman, D.B., Davidson, J.H., Stein, A., 2013. Enhanced oxidation kinetics in thermochemical cycling of $\mathrm{CeO} 2$ through templated porosity. J. Phys. Chem. C 117, 1692-1700. doi:10.1021/jp309247c

Scheffe, J.R., Jacot, R., Patzke, G.R., Steinfeld, A., 2013. Synthesis, Characterization, and Thermochemical Redox Performance of $\mathrm{Hf} 4+, \mathrm{Zr} 4+$, and Sc 3+ Doped Ceria for Splitting CO 2. J. Phys. Chem. C 117, 24104-24114. doi:10.1021/jp4050572

Venstrom, L.J., De Smith, R.M., Bala Chandran, R., Boman, D.B., Krenzke, P.T., Davidson, J.H., 2015. Applicability of an Equilibrium Model To Predict the Conversion of CO 2 to 
CO via the Reduction and Oxidation of a Fixed Bed of Cerium Dioxide. Energy \& Fuels 29, 8168-8177. doi:10.1021/acs.energyfuels.5b01865

Venstrom, L.J., De Smith, R.M., Hao, Y., Haile, S.M., Davidson, J.H., 2014. Efficient Splitting of CO 2 in an Isothermal Redox Cycle Based on Ceria. Energy \& Fuels 28, 2732-2742. doi:10.1021/ef402492e

Venstrom, L.J., Petkovich, N., Rudisill, S., Stein, A., Davidson, J.H., 2012. The Effects of Morphology on the Oxidation of Ceria by Water and Carbon Dioxide. J. Sol. Energy Eng. 134, 011005. doi:10.1115/1.4005119

Young, I.T., 1977. Proof without prejudice: use of the Kolmogorov-Smirnov test for the analysis of histograms from flow systems and other sources. J. Histochem. Cytochem. 25, 935-941. doi:10.1177/25.7.894009

Zhang, W., Sachenko, P., Schneibel, J.H., Gladwell, I., 2002. Coalescence of two particles with different sizes by surface diffusion. Philos. Mag. A 82, 2995-3011.

doi:10.1080/01418610210164366 